\title{
Certain Improvements in Alzheimer Disease Classification using Novel Fuzzy c Means Clustering for Image Segmentation
}

\author{
K.P. Kaliyamurthie, G.Michael, C.Anuratha, B.Sundaraj
}

\begin{abstract}
The Medical images are the diagnostic evidence that ensures information on the anatomical pathology. In the field of medical imaging, the automatic classification and its retrieval can insert in a new radiograph inside the current archive without manual interaction and also can search for specific diagnoses based on the image input. The image retrieval brings down the cost of medical care to a great extent as the clinical decision of the physician is faster because the anatomical features and also the pathologic appearance is compared to that of an image database. Dementia is a neurological condition that describes the problems with memory as well as thinking. It denotes the progressive deterioration of thoughts and interferes severely with the social, the occupational as well as the intellectual functioning. Dementia is because of a brain disease and not because of ageing. Most of the people go through a memory loss that is linked to ageing but it does not affect the daily functions and is not connected to dementia.
\end{abstract}

Keywords : Radiograph, Demaentia, Diagnosis

\section{INTRODUCTION}

The Classification is fundamental in applications like in the retrieval systems of medical imaging. This classification tries to get a learning algorithm for the construction of a classifier with class labels (Yang, J., \& Deng, T 2013). A classifier normally assigns a class label to examples. The building cataloging model (Categorize) contains preprocessing as well as removal of graphic articles from the tagged images (i.e. practicing set). The classifier proposed classifies MRI images for examination of Alzheimer's disease (AD). The extraction of feature in MRI image is done using wavelet transform and the MRI images are segmented and classified into normal and abnormal by the Fuzzy Bee based Bagging and Boosting classifier.[1]to[10]

The main objective of the research is

Revised Manuscript Received on July 22, 2019.

K.P. Kaliyamurthie, Department of Computer Science and Engineering, Bharath Institute of Higher Education and Research, Chennai. Email: kpkaliyamurthie@gmail.com

G.Michael, Department of Computer Science and Engineering, Bharath Institute of Higher Education and Research, Chennai. Email: micgeo270479@gmail.com

C.Anuratha, Department of Computer Science and Engineering, Bharath Institute of Higher Education and Research, Chennai. Email: anuradha.ak23@gmail.com

B.Sundaraj, Department of Computer Science and Engineering, Bharath Institute of Higher Education and Research, Chennai.Email: sundarrajboobalan@gmail.com
- Evaluation of the performance of the bagging and boosting classifiers to classify the MRI images as normal and anomalousfor Alzheimer's disease (AD).

- Evaluation of performance of Fuzzy C-Means offor effective medical image segmentation even in the case of data set with noisy images and[11-20]

- Propose Fuzzy Bee Segmentation for enhancing medical image segmentation even in anomalous images by considering neighborhood information and thus improve the classification of brain images.[21]

\section{B. Enactment Assessment Of Trapping And Improving For Alzheimer's Disease}

The Open Access Series of Imaging Studies (OASIS) data set is used for experiments conducted in this study. This Wavelet texture features are extracted from the images. Boosting and Bagging,K Nearest Neighbor and Naïve Bayes algorithms arethe classifiers used for evaluating their performance in classifying data for Alzheimer's disease[21-31].

\section{METHODOLOGY}

The Open Access Series of Imaging Studies (OASIS)is the scheme for creation the Magnetic Resonance Imaging data of the brain set to the methodical communities. The initial set of OASIS of the MRI data is included in about 400 demented and non-demented individuals in the adult lifespans (Lapuyade-Lahorgue, J et al 2017). This data includes the MRI data that is longitudinal of 150 people ranging between the age of 60 and 96 that included about 64 of them having mild AD that was clinically diagnosed. The OASIS had a screening process which included a patient information as well as MRI acquisition along with 2 clinical tests for assessing the cognitive performance of the subject which includes Clinical Dementia Rating (CDR) and Mini-Mental State Examination (MMSE). The former is an elaborate and time-consuming test that has discerning even mild dementia (Khadidos, A et al 2017) and the latter is a common questionnaire in which a score of $27 / 30$ is taken as normal (Marcus et al 2010). A CDR score of 0 shows there is no dementia but higher scores mean severity of the same.[31] If it is used for analysis of theimage, the wavelet transform is calculated by applying a separable filter bankto theimage according to equation (1) (Akgül et al 2009): 


$$
\begin{aligned}
& A_{n}=\left(H_{x} *\left(H_{y} * A_{n-1}\right)_{\downarrow_{2,1}}\right)_{\downarrow_{1,2}} \\
& H_{n}=\left(G_{x} *\left(H_{y} * A_{n-1}\right)_{\downarrow_{2,1}}\right)_{\downarrow_{1,2}} \\
& V_{n}=\left(G_{x} *\left(H_{y} * A_{n-1}\right)_{\downarrow 2,1}\right)_{\downarrow_{1,2}} \\
& D_{n}=\left(G_{x} *\left(G_{y} * A_{n-1}\right)_{\downarrow_{2,1}}\right)_{\downarrow_{1,2}}
\end{aligned}
$$

In which $*$ denotes 2 -dimensional complication, $\downarrow$ denotes the down-sampling of dimension by a factor, and $H$ a low pass filter, $G$ is high pass filter. $A$, an approximation image is obtained by a lowpass filtering in two directions, and detail coefficients $H_{n}, V_{n}$, and $D_{n}$ are derived by great pass filtering in more than one direction. A feature extracted from the wavelet coefficients is the average energy of each detail image which is a sum of squares of the detail image normalized for the entire coefficients in the image[34-40].

(1)

Bagging is on the basis of bootstrapping as well as aggregating concepts. The former is a random sampling that is based on a sampling of replacement (Busch et al 2002). So, by taking a replicate of

bootstrap $X^{b}=\left(X_{1}^{b}, X_{2}^{b}, \ldots, X_{n}^{b}\right)$ (that is a

random selection replacement) of the training set $X=\left(X_{1}, X_{2}, \ldots, X_{n}\right)$, it has to be avoided to get lower misleading objects of training in the training set of the bootstrap. So a classifier is constructed based on a training set that has the better performance. The aggregation is the combination of classifiers[19-22]. Most often a combined classifier gives better results than that of the individual classifiers.

For Bagging, both bootstrapping and aggregating are used: (Tallapragada, V. S et all 2016).Boosting,however, combines weak classifiers and poor performance for getting a classification rule with an improved performance.

A memory based model for being fit is the k-Nearest Neighbor classifier $(\mathrm{kNN})$. The test point $\mathrm{x}_{(\text {test })}$ is considered and training points in a training set $\mathrm{Y}$ in which $Y=\left\{y_{1}, y_{2}, \ldots, y_{n}\right\}$ in case the training set contains $\mathrm{n}$ points. So for the test point, the $\mathrm{k}$ training points of training set $\mathrm{Y}$ have been found to have a close distance to $\mathrm{x}_{(t e s t)}$. $\mathrm{x}_{(t e s t)}$ which is classified by using $\mathrm{k}$ neighbors' majority votes. In case the features are real-valued, the Euclidean distance is made use of in the feature space and is shown in equation (2) (Skurichina et al 2002):

$$
d_{i}=\left\|y_{i}-x_{(t e s t)}\right\|
$$

In which $i$ denotes specific index of the points in the training set. The k-NN pattern classifier is an effective learner of the domains of recognition of general patterns. Their appeal is owing to the simplicity of concept and easy implementation[23-27].

The Naive Bayes is a method of classification which is very popular and based on the Bayes theory. It is further based on the estimation of conditional density and probability of class prior, which is a test data point and the probability of the posterior class. A main issue in the Naïve Bayes method is the estimation of conditional density. This classifier makes the assumption that the specific feature's value is not related to the value of the others and the equation (3) proves this $(\mathbf{L i}$, B. $\mathbf{N}$ et all 2016):

$$
P\left(x \mid C_{k}\right)=\prod_{j=1}^{d} P\left(x^{j} \mid C_{k}\right)
$$

The Naive Bayes classifier also applies the Bayes' theorem with independent and strong assumptions. This is also termed as the "independent feature model". In simple terms, the Naïve Bayes classifier makes the assumption that either the presence or the absence of other features. Even in cases where the features are dependent on the other existing features the Naïve Bayes classifier takes into consideration all the properties that contribute independently to the probability[28-30]. Results: These experiments have been conducted by using image samples of OASIS data set and the results are duly compared with other techniques. Table 1 depicts the results of the accuracy of classification of both boosting and bagging.Table 1 Results of Classification Accuracy of Boosting and Bagging

\begin{tabular}{|l|c|}
\hline \multicolumn{1}{|c|}{ Techniques } & Classification Accuracy \\
\hline Naïve Bayes & 0.8556 \\
\hline kNN & 0.8627 \\
\hline Bagging & 0.919 \\
\hline Boosting & 0.912 \\
\hline
\end{tabular}

The Bagging algorithm improved classification accuracy by $7.1453 \%$ than Naïve Bayes and by $6.3198 \%$ than $\mathrm{kNN}$. The boosting algorithm improved classification accuracy by

$6.3815 \%$ than Naïve Bayes and by $5.5559 \%$ than $\mathrm{kNN}$.

\section{A. Performance Evaluation of Fuzzy C-Means For Medical Image Segmentation}

Here, the wavelet articles, the FCM, the improving and the tapping methods have been described for segmentation of medical image. The Fuzzy C Means (FCM) suggested is an approach used widely for segmenting the medical images even though it is taken as image intensity and so the outcomes that are not adequate turn out to be noise-filled The classifiers like bagging and boosting are common in resampling the ensemble. They can also create and merge many classifiers by using the same learning model for the base classifiers[31-33].

\section{Methodology:}

The images are denoted in the feature spaces in which the FCM makes a classification of images by clubbing identical data points as clusters. This takes place by means of iterative minimization of the cost functions that rely upon the distance

Published By: 
of the pixels and the cluster centers in the feature domain (Cao X et al 2016).

The Mock code for the fuzzy c- means is as below:

1. Setting of the number of groups along with their centers.

2. Computing of the association rank of all the data ideas.

3. Apprising of the group centers.

4. Reiterating the stages 2 and 3 till impartial occupations reach a smallest.

This is the basis of the minimization of the impartial functions in the equation (4):

$J=\sum_{i=1}^{N} \sum_{j=1}^{C} u_{i j}^{m}\left\|x_{i}-c_{j}\right\|^{2} \quad 1 \leq m \leq \infty$

In which $\mathrm{m}$ denotes a real number that is bigger than $1, u_{i j}$ the degree of membership of $x_{i}$ in cluster $\mathrm{j}, x_{i}$ the $\mathrm{i}^{\text {th }}$ of d-dimensional data that is measured, ${ }^{c}{ }_{j}$ the d-dimension center of clusters, and $\|*\|$ is the norm denoting the similarity between the assessed data and center.

The performance of Fuzzy partitioning by an iterative optimization of an objective function given, with updating of membership $u_{i j}$ and cluster centers $c_{j}$ as in equation $(5,6)$ :

$$
\begin{aligned}
u_{i j} & =\frac{1}{\sum_{k=1}^{C}\left(\frac{\left\|x_{i}-c_{j}\right\|}{\left\|x_{i}-c_{k}\right\|}\right)^{\frac{2}{m-1}}} \\
c_{j}= & \frac{\sum_{i=1}^{N} u_{i j}^{m} \cdot x_{i}}{\sum_{i=1}^{N} u_{i j}^{m}}
\end{aligned}
$$

below:

The iteration is terminated if the equation (7) is as

$$
\max _{i j}\left\{\left|u_{i j}^{(k+1)}-u_{i j}^{(k)}\right|\right\}<\theta
$$

In which $\theta$ is a form of termination amid 0 and 1 when $\mathrm{k}$ is the stage of iteration. This method joins into a limited least or the burden point $J_{m}$.

The Fuzzy c-means has some disadvantages, it is efficient in terms of health MRIs of brain but not efficient in anomalous images which are edemas and brains with tumors. The FCM handles intensities of the pixel and does not consider characteristics of the neighborhood. The center for random cluster, process of choosing the FCM forces the process for getting jammed in the limited targets with ease. The possible answers come over techniques of optimization. The objective function values and their solutions are called optimal solutions.

Results: Figure 1 shows results of classification accuracy of FCM Segmentation.

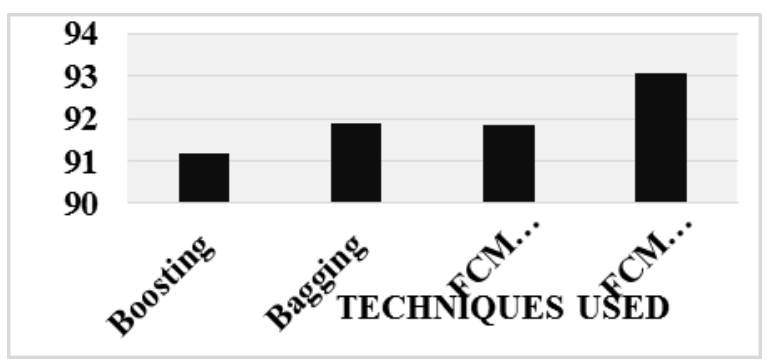

Figure 1 Classification Accuracy of FCM Segmentation

Figure 1 shows that the FCM Segmentation-Bagging algorithm improved classification accuracy by $2.01 \%$ than Boosting, by $1.25 \%$ than Bagging and by $1.32 \%$ than FCM Segmentation-Boosting.

\section{Fuzzy Bee Segmentation - Metaheuristic Approach For The Medical Image Segmentation Problem}

The segmentation of Fuzzy bee is used for better accuracy by bagging and boosting.

Methodology: The Artificial Bee Colonies are a additional new model of universal optimization built by Karaboga. It is inspired by the honey bees' foraging activity. From this very inception, the Artificial Bee Colony is employed broadly and effectively in many issues of optimization[34-35].

In the $\mathrm{ABC}$, all locations of food sources indicate certain issues when the nectar's quantity indicates value of fitness. Inside the hives, three types of bees are present: the employed, the onlooker and the scout bees. The number of employed and onlooker bees is equal to the quantity of the present solutions in the population of solutions. The ABC contains a set of cycles. For each cycle, there are three components. 1) ensuring the employed bees move to the source of food and assessing the nectar quantity. 2) onlooker bees choosing food sources. 3) defining the scout bees and exploring fresh sources of food.

First, $\mathrm{ABC}$ creates an original population that is arbitrary for NP solutions, D dimensional vectors and $\mathrm{D}$ is the optimization variable quantity (Balasubramani \& Marcus 2013).

For creating the first solution for $\mathrm{i}^{\text {th }}$ employed bee, the equation (8) is used.

$$
\begin{aligned}
& x_{i j}=x_{\min }^{j}+\operatorname{rand}(0,1) \times\left(x_{\max }^{j}-x_{\min }^{j}\right) \\
& \left(i=1, \ldots \ldots, N_{p} \text { and } j=1, \ldots, D\right)
\end{aligned}
$$

In which the $x_{\min }^{j}$ and $x_{\max }^{j}$ denotes the minor bound and the higher bound of $\mathrm{j}^{\text {th }}$ element of solution $z_{i, j}$.

As soon as the initialization is completed all the employed bees go in search of the neighborhood for sources of food in their memory and future change it by equation (9).

$$
\begin{aligned}
& u_{i j}=x_{i j}+\varphi_{i j} *\left(v_{i j}-x_{k j}\right) \\
& \left(i, k=1, \ldots, N_{p}, i \neq \text { kand } j=1, \ldots, D\right)
\end{aligned}
$$

The Employed bees update memory with the 
answers that are novel in case the value is enhanced or the older answers are taken and their trajectories are increased by 1 and this implies that the answers are not rightly improved. As soon as all the engaged bees dismiss the procedure of search and this knowledge is joint with that of the spectator bees. All the onlooker bees are lead to the bases of food with a chance $\mathrm{p}_{\mathrm{i}}$ according to the equation given (10):

$$
p_{i}=\frac{\text { fit }_{i}}{\sum_{k=1}^{N_{p}} f_{i t}}\left(i=1, \ldots, N_{p}\right)
$$

As soon as the sources are selected the onlookers get the potential locations of thefood source from the memory by using equation (9). As in the case of employed bees, the onlookers make an evaluation of the novel situations and also contrast the aptness with those in their memory. If the new one has the same value than that of the earlier ones the ancient ones are replaced with new answers. If not, the earlier answers are duly upheld and the trails are increased by 1.

As soon as all the onlookers update their solutions the one that has the highest trail value is taken. Once the solution's trail goes beyond a particular limit, the solution is abandoned and the working bee changes into a spy bee which arbitrarily gives newer solutions by equation (6) and also differences capability of new answers and also the ancient ones. In case the new answers are better than the elder ones they will be substituted and the trace value will be reset to 0 . The spies are malformed into working bees.

This process is repeated till the extreme number of series $\mathrm{MCN}$ is reached. The Optimal solutions are indicated by the bees that have higher values of fitness.

\section{B. ABC-FCM}

In the initial stages, the ABC-Fazzy c-mean algorithm makes use of the worldwide searches in $\mathrm{ABC}$ for searching for answers that are optimal as the early grouping hubs for the Fazzy c-means. Next, the algorithm proposed uses the Fuzzy c-means for optimization of the early centers of grouping and also to capture the global optima. [41]

The ABC-FCM brings about an randomly dispersed populace of the $\mathrm{SN}$ answers in which the $\mathrm{SN}$ denotes the working or onlooker bees and their size. So the bees here represent the cluster centers. All the solutions $\mathrm{x}_{\mathrm{i}}(\mathrm{i}=1,2 \ldots \ldots$ $\mathrm{SN}$ ) are the vectors that are D-dimensional that have D as the optimization variable quantity. The food sources indicate the solutions to this issue that is optimized when the nectar quantity of the sources of food correlates to the particular solutions. This is shown in Equation (11):

$$
\text { fit }_{i}=\frac{1}{1+f_{i}}=\frac{1}{1+J_{m}(U, V)}
$$

In which $J_{m}(\mathrm{U}, \mathrm{V})$ denotes the impartial function of the Fazzy c-mean. The lesser the $J_{m}(\mathrm{U}, \mathrm{V})$ value the greater the separate aptness and the result of grouping is also better. [35-39]

In the ABC-FCM, if a location cannot get enhanced by a set of cycle quantity, the foodstuff source is taken to be uncontrolled and if that source is $\mathrm{x}_{\mathrm{i}}$, then, a novel food source is found by the scout for being substituted with $\mathrm{x}_{\mathrm{i}}$. This operation is given by equation (12) (Kalavathi, P., \& Priya, T 2016):

$$
x_{i}^{j}=x_{\min }^{j}+\operatorname{rand}[0,1]\left(x_{\max }^{j}-x_{\min }^{j}\right)
$$

The ABC-FCM is a search procedure that is robust; the exploitation and exploration are both concurrently performed. The algorithm's global searches mainly depend on the search procedure that is arbitrary by the scouts and the production of neighbor solution of the onlooker bees. So the ABC-FCM is an optimization technologythat is effective and this merges the exploitation (the limited examines) with the investigation (the global searches).

The procedure shown below defines the stages that are followed by the ABC-FCM technique:

1. Set the variables of $\mathrm{ABC}$ and FCM so thatthe population size $\mathrm{SN}$, the maximum cycle number $\mathrm{MCN}$, and the cluster number $\mathrm{C}, \mathrm{m}, \varepsilon$;

2. Set the matrix of membership U;

3. Create an initial population (the cluster centre) $c_{i j}$ andevaluate the fitness of the population;

4. With:

a. Cycle=1,

b. $s=1$,

c. Providing fresh solutions $\mathrm{u}_{\mathrm{ij}}$ for the employed bees and also evaluate them,

Employing of greedy selection procedures for the employed bees, Computing of probability values $P_{i}$ for the solutions $u_{i j}$, 5. Providing of fresh solutions $u_{i j}$ for the onlookers from the solution $\mathrm{c}_{\mathrm{ij}}$ chosen based on $\mathrm{P}_{\mathrm{i}}$ and also valuate them,

6. Employing a greedy selection procedure for the onlooker s,

7. If the searching time around the employed bees is greater than the specified limit and the improved solutions have not been discovered, the position vectors can be reset arbitrarily according to Step b.

8. If the values of iteration are higher than the iterations' maximum quantity (i.e. cycle $>\mathrm{MCN}$ ), and the output isthemost optimal cluster center. If not, go to Step a.

9. Updating of the membership matrix $\mu_{i k}^{t}$. Updating of cluster centers $v_{i k}^{t}$;

10. If $\max _{i, k}\left|\mu_{i k}^{t}-\mu_{i k}^{t-1}\right| \leq \varepsilon$, then stop. If not, return to Step 5 and stop if the criterion is fulfilled.

Results: For this section, an FCM segmentation that uses the boosting as well as the bagging methods and also the Fuzzy Bee segmentation with these two methods are evaluated here. The Table 2 shows the classification accuracy results for both boosting and bagging.

Table 2 Results of Classification Accuracy of Fuzzy Bee Segmentation

\begin{tabular}{|l|l|}
\hline Techniques used & $\begin{array}{l}\text { Classification } \\
\text { Accuracy }\end{array}$ \\
\hline FCM Segmentation- Boosting & 91.84 \\
\hline FCM Segmentation - Bagging & 93.06 \\
\hline $\begin{array}{l}\text { Published By: } \\
\text { Blue Eyes Intelligence Engineering } \\
\text { \& Sciences Publication }\end{array}$ & \begin{tabular}{c} 
Sexploring \\
\hline
\end{tabular}
\end{tabular}




\begin{tabular}{|l|l|}
\hline $\begin{array}{l}\text { Fuzzy Bee Segmentation - } \\
\text { Boosting }\end{array}$ & 94.29 \\
\hline Fuzzy Bee Segmentation Bagging & 95.92 \\
\hline
\end{tabular}

From the table 2, it can be perceived that this method increased classification accuracy by $4.34 \%, 3.02 \% \& 1.71 \%$ when compared with Fazzy C-Means SegmentationBoosting, Fazzy C-Means Segmentation - Bagging and Fuzzy Bee Segmentation - Boosting methods.

\section{CONCLUSION}

Bagging and boosting are the most popular methods of resampling ensemble that generate as well as combine a variety of classifiers that use similar learning algorithms for the base classifiers. The boosting algorithms are stronger than that of the bagging in terms of noise free data. The boosting method brings down the errors of weak learning algorithms that generate the classifiers which are better than the random guessing. The OASIS dataset is utilized for the sample images for conducting experiments. Both bagging and boosting perform better than other classifiers. The results proved that the accuracy of classification improved when compared to other classifiers.

Segmentation is considered to be an important step in the image analysis and the computer vision and is a research area even though the literature available is dense. The spatial information being incorporated into the FCM's objective function gives successful results for both a robust and an effective segmentation of images that are noisy.

Both the methods are used for this. The results show the FCM Segmentation-Bagging algorithm has an improved accuracy of classification by about $2.01 \%$ than that of Boosting, by about $1.25 \%$ than that of Bagging and by about $1.32 \%$ than that of FCM Segmentation-Boosting. The Fuzzy Bee Segmentation Bagging method had an increased accuracy of classification by about $4.34 \%, 3.02 \%$ \& $1.71 \%$ in comparison to the FCM Segmentation- Boosting, the FCM Segmentation - Bagging and the Fuzzy Bee Segmentation Boosting methods.

- Evaluation of the performance of the bagging and boosting classifiers to classify the MRI images as normal and anomalousfor Alzheimer's disease (AD).

- Evaluation of performance of Fuzzy C-Means offor effective medical image segmentation even in the case of data set with noisy images and[11-20]

- Propose Fuzzy Bee Segmentation for enhancing medical image segmentation even in anomalous images by considering neighborhood information and thus improve the classification of brain images.[21]

\section{REFERENCES}

[1] Kumaravel A., Rangarajan K.,Algorithm for automaton specification for exploring dynamic labyrinths,Indian Journal of Science and Technology,V-6,I-SUPPL5,PP-4554-4559,Y-2013

[2] P. Kavitha, S. Prabakaran "A Novel Hybrid Segmentation Method with Particle Swarm Optimization and Fuzzy C-Mean Based On Partitioning the Image for Detecting Lung Cancer" International Journal of

Engineering and Advanced Technology (IJEAT) ISSN: 2249-8958, Volume-8 Issue-5, June 2019

[3] Kumaravel A., Meetei O.N.,An application of non-uniform cellular automata for efficient cryptography,2013 IEEE Conference on Information and Communication Technologies, ICT 2013,V-,I-,PP-1200-1205,Y-2013

[4] Kumarave A., Rangarajan K.,Routing alogrithm over semi-regular tessellations,2013 IEEE Conference on Information and Communication Technologies, ICT 2013,V-,I-,PP-1180-1184,Y-2013

[5] P. Kavitha, S. Prabakaran "Designing a Feature Vector for Statistical Texture Analysis of Brain Tumor" International Journal of Engineering and Advanced Technology (IJEAT) ISSN: 2249-8958, Volume-8 Issue-5, June 2019

[6] Dutta P., Kumaravel A.,A novel approach to trust based identification of leaders in social networks,Indian Journal of Science and Technology,V-9,I-10,PP--,Y-2016

[7] Kumaravel A., Dutta P.,Application of Pca for context selection for collaborative filtering,Middle - East Journal of Scientific Research,V-20,I-1,PP-88-93,Y-2014

[8] Kumaravel A., Rangarajan K.,Constructing an automaton for exploring dynamic labyrinths,2012 International Conference on Radar, Communication and Computing, ICRCC 2012,V-,I-,PP-161-165,Y-2012

[9] P. Kavitha, S. Prabakaran "Adaptive Bilateral Filter for Multi-Resolution in Brain Tumor Recognition" International Journal of Innovative Technology and Exploring Engineering (IJITEE) ISSN: 2278-3075, Volume-8 Issue-8 June, 2019

[10] Kumaravel A.,Comparison of two multi-classification approaches for detecting network attacks, World Applied Sciences Journal,V-27,I-11,PP-1461-1465,Y-2013

[11] Tariq J., Kumaravel A.,Construction of cellular automata over hexagonal and triangular tessellations for path planning of multi-robots,2016 IEEE International Conference on Computational Intelligence and Computing Research, ICCIC 2016,V-,I-,PP--,Y-2017

[12] Sudha M., Kumaravel A.,Analysis and measurement of wave guides using poisson method,Indonesian Journal of Electrical Engineering and Computer Science,V-8,I-2,PP-546-548,Y-2017

[13] Ayyappan G., Nalini C., Kumaravel A.,Various approaches of knowledge transfer in academic social network, International Journal of Engineering and Technology,V-,I-,PP-2791-2794,Y-2017

[14] Kaliyamurthie, K.P., Sivaraman, K., Ramesh, S. Imposing patient data privacy in wireless medical sensor networks through homomorphic cryptosystems 2016, Journal of Chemical and Pharmaceutical Sciences92.

[15] Kaliyamurthie, K.P., Balasubramanian, P.C. An approach to multi secure to historical malformed documents using integer ripple transfiguration 2016 Journal of Chemical and Pharmaceutical Sciences92.

[16] A.Sangeetha,C.Nalini,"Semantic Ranking based on keywords extractions in the web", International Journal of Engineering \& Technology, 7 (2.6) (2018) 290-292

[17] S.V.GayathiriDevi,C.Nalini,N.Kumar,"An efficient software verification using multi-layered software verification tool "International Journal of Engineering \& Technology, 7(2.21)2018 454-457

[18] C.Nalini,ShwtambariKharabe,"A Comparative Study On Different Techniques Used For Finger - Vein Authentication", International Journal Of Pure And Applied Mathematics, Volume 116 No. 82017 , 327-333, Issn: 1314-3395

[19] M.S. Vivekanandan and Dr. C. Rajabhushanam, "Enabling Privacy Protection and Content Assurance in Geo-Social Networks", International Journal of Innovative Research in Management, Engineering and Technology, Vol 3, Issue 4, pp. 49-55, April 2018.

[20] Dr. C. Rajabhushanam, V. Karthik, and G. Vivek, "Elasticity in Cloud Computing", International Journal of Innovative Research in Management, Engineering and Technology, Vol 3, Issue 4, pp. 104-111, April 2018.

[21] K. Rangaswamy and Dr. C. Rajabhushanamc, "CCN-Based Congestion Control Mechanism In Dynamic Networks”, International Journal of Innovative Research in Management, Engineering and Technology, Vol 3, Issue 4, pp. 117-119, April 2018.

[22] Kavitha, R., Nedunchelian, R., "Domain-specific Search engine optimization using healthcare ontology and a neural network backpropagation approach", 2017, Research Journal of 


\section{Certain Improvements in Alzheimer Disease Classification using Novel Fuzzy c Means Clustering for Image Segmentation}

Biotechnology, Special Issue 2:157-166

[23] Kavitha, G., Kavitha, R., "An analysis to improve throughput of high-power hubs in mobile ad hoc network", 2016, Journal of Chemical and Pharmaceutical Sciences, Vol-9, Issue-2: 361-363

[24] Kavitha, G., Kavitha, R., "Dipping interference to supplement throughput in MANET" , 2016, Journal of Chemical and Pharmaceutical Sciences, Vol-9, Issue-2: 357-360

[25] Michael, G., Chandrasekar, A.,"Leader election based malicious detection and response system in MANET using mechanism design approach", Journal of Chemical and Pharmaceutical Sciences(JCPS) Volume 9 Issue 2, April - June 2016.

[26] Michael, G., Chandrasekar, A.,"Modeling of detection of camouflaging worm using epidemic dynamic model and power spectral density", Journal of Chemical and Pharmaceutical Sciences(JCPS) Volume 9 Issue 2, April - June 2016 .

[27] Pothumani, S., Sriram, M., Sridhar, J., Arul Selvan, G., Secure mobile agents communication on intranet,Journal of Chemical and Pharmaceutical Sciences, volume 9, Issue 3, Pg No S32-S35, 2016

[28] Pothumani, S., Sriram, M., Sridhar , Various schemes for database encryption-a survey, Journal of Chemical and Pharmaceutical Sciences, volume 9, Issue 3, Pg NoS103-S106, 2016

[29] Pothumani, S., Sriram, M., Sridhar, A novel economic framework for cloud and grid computing, Journal of Chemical and Pharmaceutical Sciences, volume 9, Issue 3, Pg No S29-S31, 2016

[30] Priya, N., Sridhar, J., Sriram, M. "Ecommerce Transaction Security Challenges and Prevention Methods- New Approach" 2016 ,Journal of Chemical and Pharmaceutical Sciences, JCPS Volume 9 Issue 3.page no:S66-S68 .

[31] Priya, N.,Sridhar,J.,Sriram, M."Vehicular cloud computing security issues and solutions" Journal of Chemical and Pharmaceutical Sciences(JCPS) Volume 9 Issue 2, April - June 2016

[32] Priya, N., Sridhar, J., Sriram, M. "Mobile large data storage security in cloud computing environment-a new approach" JCPS Volume 9 Issue 2. April - June 2016

[33] Anuradha.C, Khanna.V, "Improving network performance and security in WSN using decentralized hypothesis testing "Journal of Chemical and Pharmaceutical Sciences(JCPS) Volume 9 Issue 2, April - June 2016.

[34] Anuradha.C, Khanna.V, "A novel gsm based control for e-devices" Journal of Chemical and Pharmaceutical Sciences(JCPS) Volume 9 Issue 2, April - June 2016 .

[35] Anuradha.C, Khanna.V, "Secured privacy preserving sharing and data integration in mobile web environments " Journal of Chemical and Pharmaceutical Sciences(JCPS) Volume 9 Issue 2, April - June 2016.

[36] Sundarraj, B., Kaliyamurthie, K.P. Social network analysis for decisive the ultimate classification from the ensemble to boost accuracy rates 2016 International Journal of Pharmacy and Technology

[37] Sundarraj, B., Kaliyamurthie, K.P. A content-based spam filtering approach victimisation artificial neural networks 2016 International Journal of Pharmacy and Technology83.

[38] Sundarraj, B., Kaliyamurthie, K.P. Remote sensing imaging for satellite image segmentation 2016 International Journal of Pharmacy and Technology8 3 .

[39] Sivaraman, K., Senthil, M. Intuitive driver proxy control using artificial intelligence 2016 International Journal of Pharmacy and Technology84

[40] Sivaraman, K., Kaliyamurthie, K.P. Cloud computing in mobile technology 2016 Journal of Chemical and Pharmaceutical Sciences92.

[41] Sivaraman, K., Khanna, V. Implementation of an extension for browser to detect vulnerable elements on web pages and avoid click jacking 2016 Journal of Chemical and Pharmaceutical Sciences92.

\section{AUTHORS PROFILE}

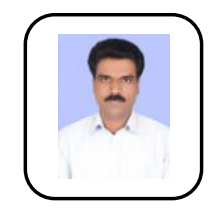

K.P.Kaliyamurthie, Professor, Department of Computer Science \& Engineering, Bharath Institute of Higher Education and Research, Chennai, India

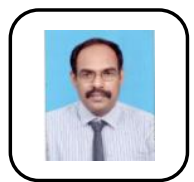

G.Michael, Assistant Professor, Department of Computer Science \& Engineering, Bharath Institute of Higher Education and Research, Chennai, India

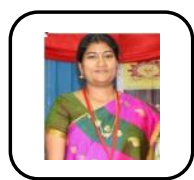

C.Anuratha Assistant Professor, Department of Computer Science \& Engineering, Bharath Institute of Higher Education and Research, Chennai, India

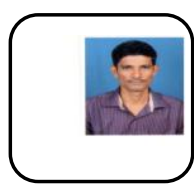

B.Sundaraj Assistant Professor, Department of Computer Science \& Engineering, Bharath Institute of Higher Education and Research, Chennai, India 